\title{
EDITORIAL
}

\section{One hundred MEPS volumes: their pages have shaped the world of marine ecological research}

\author{
O. Kinne \\ Ecology Institute, Nordbünte 23, D-21385 Oldendori/Luhe, Germany
}

Hard to believe but true, Marine Ecology Progress Series (MEPS) is a volume centenarian at the youthful age of 14 !

The short history of MEPS is one of unparalleled success. MEPS is the acknowledged leader among marine biological and marine ecological core journals world wide. This was first determined in 1988 (see my Editorial marking the appearance of Volume 50; Mar. Ecol. Prog. Ser. 50:1-2) and this is confirmed in 1993 by Pudovkin (see his note in this centenary volume, p. 207-209).

Research articles, reviews and notes published in MEPS are carefully selected, critically reviewed and quality-improved, and they are professionally copyedited and type-set by an in-house team of experts. The papers published in MEPS have become quality symbols.

The appearance of Volume 100 gives me, the founder and editor of MEPS, a welcome opportunity to thank all those who have been instrumental in the journal's success: the Editorial Advisors and Referees who form the scientific backbone of MEPS; the editorial staff who perform the copy-editing, and who have mastered the task of combining these skills with newly acquired expertise in type-setting; and the administrative and secretarial staff of Inter-Research who attend promptly and reliably to all matters of communication between authors, editorial personnel and subscribers. I also thank the authors who have trusted us with handling their manuscripts, and the subscribers who have stayed with us despite low library budgets and multiple electronic temptations to violate copyright laws. Thank you all indeed!
We have embarked on an experiment. In order to shorten the distance between author and editor and in order to further broaden the input basis for MEPS, we have appointed 37 Editorial Advisors (EAs) to Senior EAs giving them the status of Subeditors. They may see manuscripts submitted to them through a rigorous 3-referee review process for themselves, and present manuscripts considered acceptable to the Editor (who reserves the right of final decision on acceptance or rejection). In the journal, the names of Senior EAs are marked by (S). In the past, a few EAs had already acted as Subeditors, and this has worked very well. While we shall follow the final outcome of broadening the editorial basis of MEPS with critical eyes, we hope that it will further strengthen the journal. As a new service, we will also begin including key words at the head of each article.

The attention that MEPS receives from the scientific world and the number of manuscripts submitted are still increasing. In 1994, in spite of further toughening our criteria for acceptance of papers, we will need to publish 13 volumes. Production costs have increased, but Inter-Research has decided to keep the price per volume unchanged.

So much for the good news. The bad news is that substantial increases in postage prices now force the publisher to charge for postage, handling and insurance. And Inter-Research can no longer provide free reprints. Sorry! But such is the price for keeping down the price.

The editorial staff of MEPS vows to continue to give its best for keeping MEPS what it is: the premier journal in its field. 